\section{EVALUATION OF PATCH TESTING IN CONTACT DERIMATITIS PATIENTS ATTENDING TERTIARY CARE CENTRE IN KARAIKAL}

KEY WORDS: Allergic contact dermatitis, patch testing, allergens, eczema.

\section{Dr. SivaKumar Sivasubramaniam}

\section{Dr. Ambujam Govindasamy}

Dr. Kode Leela Sravanthi*

\section{Dr.Brindha Pandiyan}

Department of Dermatology, Venerology \& Leprosy,Vinayaka Mission's Medical College and Hospital, Vinayaka Mission Research Foundation (Deemed to be University), Karaikal.

Department of General Surgery, - Vinayaka Mission's Medical College and Hospital, Vinayaka Mission Research Foundation (Deemed to be University), Karaikal.

Department of Dermatology, Venerology \& Leprosy,Vinayaka Mission's Medical College and Hospital, Vinayaka Mission Research Foundation (Deemed to be University), Karaikal. *Corresponding Author

Department of Dermatology, Venerology \& Leprosy,Vinayaka Mission's Medical College and Hospital, Vinayaka Mission Research Foundation (Deemed to be University), Karaikal.

Introduction: Allergic contact dermatitis (ACD) is a growing concern due to increased use of cosmetics and topical medications routinely and exposure to a large number of allergens on day-to-day basis. Patch testing is a reliable method for detecting the causative antigens in suspected cases.

Aims And Objectives: To assess the demographic profile, pattern of ACD, and patch test profile of suspected cases of ACD attending contact dermatitis clinic of our department.

Materials And Methods: It was a prospective study in which all the patients with suspected ACD attending OPD of department of dermatology over a 3 month period were analysed. Patch testing was done using the most common antigens primarily, and other batteries were used depending on patient requirement and availability.

Results: A total of 50 patients were enrolled in the contact dermatitis clinic over a period of 3 months. Hand eczema was the most common pattern seen in 23 cases followed by feet eczema, hand and foot eczema, facial eczema, forearm and leg eczema and photoallergic contact eczema. A total of $32(64 \%)$ gave positive patch test results, with nickel sulfate being the most common allergen identified followed by cobalt sulfate \& potassium dichromate.

Conclusion: Common allergens identified in our study were more or less similar to studies from other parts of India

\section{INTRODUCTION}

Contact dermatitis is an inflammatory response of skin to an exogenous substance which may be irritant (or) allergen. ${ }^{1,2,3}$ Contact dermatitis is divided into major types, contact irritant dermatitis (CID), and contact allergic dermatitis (CAD), both of which include contact urticaria and photo contact dermatitis. ${ }^{4}$ Contact allergic dermatitis, CAD is due to delayed cell mediated allergic reaction to allergens that directly contact the skin. Most allergens in contact dermatitis are of low molecular weight (< 500 daltons) and are traditionally called "haptens". These haptens must link with proteins to form complete antigen before they are able to sensitize.

CD accounts for approximately $90 \%$ of the skin diseases in occupational environment. ${ }^{5,6}$ The introduction of new potential sensitizers will increase the incidence of contact dermatitis. A large number of allergens are present in our environment and are encountered daily in the form of cosmetics, skin care products, hair dyes, medications, accessories, jewellery, cement, plants, and so on. Nickel found in metal industry and household objects along with fragrances and preservatives are the most common allergens responsible for causing a significant number of cases of $A C D$ globally.

Accordingly, ACD is seen in a large number of occupational groups, with the frequency and pattern varying from one group to another. In many countries, occupational contact dermatitis ranks first among occupational diseases worldwide resulting in significant morbidity and work loss days. ${ }^{10}$ Patch testing is a reliable method for detecting the causative antigen(s) in suspected cases. The allergens that are included in standard series vary from country to country based on the local experience. ${ }^{2}$
Knowledge about the responsible allergen for ACD helps a long way in reducing morbidity in such cases by identifying the incriminating allergen and can thus help minimize the impact of ACD in the affected individuals. With this background, we attempted to assess the demographic profile, pattern of ACD, and patch test profile of suspected cases of ACD attending contact dermatitis clinic of our department over a 3 month period.

\section{MATERIALS AND METHODS}

It is an Open label, prospective clinical study. 50 patients attending Dermatology outpatient department at the Vinayaka Missions Hospital, Karaikal, and Puducherry with suspected ACD from May 2021 to July 2021 were taken for study. Approval from Institutional Ethical Committee was obtained, before starting the clinical study. Written informed consent was obtained in local vernacular language from every patient before enrolment. A detailed history including the demographic data, occupational details, and exposure to different allergens was taken which was followed by clinical examination and relevant photographs for documentation. The various patterns of ACD observed were categorized into various groups like hand eczema involving primarily the dorsal and palmar aspects of fingers and hands upto the wrist. Foot eczema involving primarily the dorsal and plantar aspects of feet upto the ankle joint. Hand and foot eczema in which simultaneous involvement of both hands and feet was noticed; Facial eczema in which the eczema was seen primarily affecting the convex surfaces of the face, eyelids, lips, and periorificial area. Forearm and leg eczema where primary involvement was of the forearms and legs with nil or minimal concurrent involvement of hands and feet. Photoallergic contact eczema involving primarily the photoexposed areas such as face, $\mathrm{V}$ area of neck, and dorsal aspects of both hands and forearms with well-demarcated 
margins where the skin is covered with clothing with sparing of the Wilkinson's triangle, upper eyelids, and area under the chin and air-borne contact dermatitis (ABCD) affecting primarily the exposed areas of face, $V$ area of neck, hands, and forearms, Wilkinson's triangle, both eyelids, nasolabial folds, and area under the chin.

The involvement of both light-exposed and protected areas helps differentiate ABCD from photo-related dermatitis. Disseminated eczema was used for patients with extensive involvement of whole body, rarely proceeding to erythroderma. Nonspecific eczema was used for all such types of eczema which were not extensive but did not fit in any of the above-mentioned patterns of eczema and had a variable presentation.

All the patients (irrespective of age) were included in the study. However, patients on oral corticosteroids and other immunosupressants, pregnant, and lactating females were excluded. Those patients who had active dermatitis were patch-tested 2 weeks after their clinical symptoms subsided. Doubtful cases (requiring distinction from fungal infections, psoriasis, and other simulating dermatoses) were subjected to investigations like $\mathrm{KOH}$ mount and skin biopsy wherever necessary.

\section{TECHNIQUE OF PATCHTEST}

It is a biological test designed to detect the presence or absence of delayed type hypersensitivity or cell-mediated immunity to a specific contact allergen.

\section{Selection OfThe Patch Test Site}

In an allergic patient, the whole skin is capable of reacting with the antigen, but the patch tests are generally done on the back, because (1) it provides a large skin area for testing, (2) pressure on the back during lying down helps a better contact of the antigen with the skin (3) least immobile area (4) less hairy (5) easy to do and read patch test and (6) lesser risk of getting false negative results. ${ }^{109}$ Other sites are: upper arm and thighs, less commonly flexural surface of the forearm and abdomen.

The skin area selected for patch tests should be shaved off the coarse hairs if present at least 24 hours earlier and it should be free from any skin lesions or scars. ${ }^{3}$ Patch test should not be performed at or even near the site of a recent dermatitis because this can give rise to a false positive result. ${ }^{108}$ The acute stage of dermatitis may make the skin hyper reactive (angry back syndrome) and also there is a risk of precipitating a wide flare up of dermatitis after patch test. So it is better to wait several weeks after an acute dermatitis, for patch testing. ${ }^{5}$

\section{RESULTS}

A total of 50 patients were enrolled in the contact dermatitis clinic over a period of 3 months. Of these, 31 were females $(62 \%)$, while 19 were males (38\%). The mean age of the study population was $32.98 \pm 10.46$ years with age ranging from 10 to 72 years. In all, $32(64 \%)$ patients had a rural background, while $18(36 \%)$ were from urban areas. The mean disease duration was $4.36 \pm 1.1$ years with a range of 3 months to 8 years.

\section{Table 1}

\begin{tabular}{|l|l|}
\hline Pattern of eczema & $\begin{array}{l}\text { No. of patients with different } \\
\text { clinical patterns of eczema (\%) }\end{array}$ \\
\hline Hand eczema & 46 \\
Feet eczema & 14 \\
Hand \& foot eczema & 12 \\
Facial eczema & 8 \\
Forearm and leg eczema & 8 \\
Photoallergic contact & 6 \\
eczema & 6 \\
Air-borne contact & 2 \\
dermatitis & \\
\hline
\end{tabular}

\section{Nonspecific eczema \\ Disseminated eczema}

Total (n)

The pattern of clinical disease noticed in our study population was divided into various groups as mentioned in methodology shows the number of patients with different clinical patterns of eczema with hand eczema being the most common pattern seen in 23 cases (46\%) followed by feet eczema seen in 07 cases (14\%) hand and foot eczema in 06 cases $(12 \%)$, facial eczema in 04 cases $(8 \%)$, forearm and leg eczema in 4 cases ( $8 \%$ ), photoallergic contact eczema in 03 cases (6\%), ABCD in 1 case (2\%), nonspecific eczema in 1 case (2\%), and disseminated eczema in l case ( $2 \%$ ).

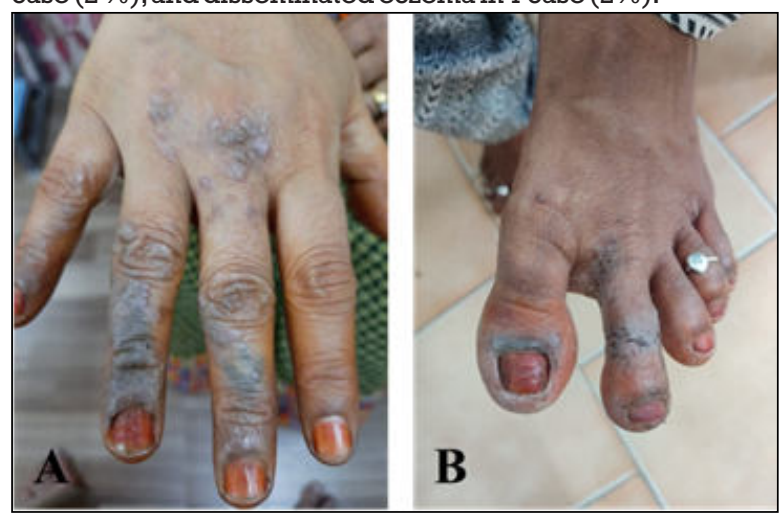

Fig 1: (A)A patient with hand eczema with positive patch test reaction to potassium dichromate (B) A patient with feet eczema with involvement of dorsal aspects of feet and toes with positive patch test reaction to nickel sulfate

Occupation-wise distribution of the study population included farmers, construction workers, housewives, artisans, and others in that order as enumerated in [Table 2].

Table 2

\begin{tabular}{|l|l|}
\hline Occupation of the patients & No. of patients in each \\
occupation (\%)
\end{tabular}

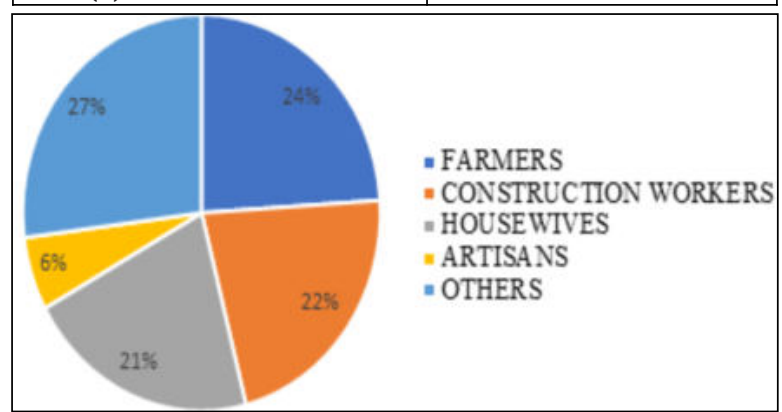

Figure 2-Occupation of the individuals

A total of 32 patients (64\%) gave positive patch test results to various allergens used. A total of 56 positive reactions were seen in these 32 patients, among which 20 patients gave a single positive reaction while 06 patients gave positive reaction to two allergens and the rest 06 patients had more than two positive patch test reactions.

Of the 56 positive reactions elicited, nickel sulfate turned out to be the most common allergen identified in 18 cases followed by cobalt chloride in 13 cases, PEG in 11 cases, potassium dichromate in 09 cases, and kathon CG in 5 cases. 


Figure 3 - Number Of Positive Reaction To Individua
Antigens
\begin{tabular}{|l|l|}
\hline Name of antigen & $\begin{array}{l}\text { No. of patients with positive } \\
\text { reactions to individual antigens } \\
(\mathbf{n = 5 6 )}\end{array}$ \\
\hline Cobalt chloride & 13 \\
Nickel sulfate & 18 \\
Potassium dichromate & 09 \\
Polyethylene glycol & 11 \\
Kathon CG & 5 \\
\hline
\end{tabular}

\section{DISCUSSION}

Clinical manifestations of ACD are highly varied, depending on the degree and frequency of contact with the allergen, the nature of the putative allergen, and host-related factors. ${ }^{4}$ The clinical presentation varies from patient to patient, often posing a diagnostic challenge to the treating dermatologist. ${ }^{6}$ In our study, the most common allergen identified was nickel sulfate which accounted for $18(32.1 \%)$ of the 56 positive patch test reactions seen in our study group .Nickel is present ubiquitously in the environment and was the most common allergen identified in females in our study. The reason for early development of nickel sensitivity in our population can be attributed to the common use of nickel-plated accessories and jewellery especially in females. As most of the population is Muslim, small girls are seen covering their heads with scarfs and using nickel-plated pins to hold the scarf in position.

Also, ear piercing is done in almost all girls at a small age and they are found wearing artificial jewellery in the form of ear rings, necklaces, rings, and bracelets. These jewellery items and other accessories like eyeglass frames, belt buckles, pins, clips, zippers, coins, and keys may release nickel as there is poor quality control on the manufacture of these items in our country. Most of the cases of nickel positivity had current relevance to the use of nickel-plated items and jewellery. ${ }^{16}$

Cobalt chloride was the second most common allergen identified in our study population. It constituted for 13 $(23.2 \%)$ positive patch test reactions. Cobalt is an invariable contaminant of nickel and is also found in cement. ${ }^{22}$ Some patients with cobalt sensitivity in our study especially females had a concomitant allergy to nickel as well.

Polyethylene Glycol was the third most common allergen in our study. It was most commonly found in females due to the exposure to PEG in the detergents, cosmetics \& shampoos. Kathon CG is other allergen most commonly found in detergents. 4 females showed sensitivity to both allergens in our study. Potassium dichromate was the fourth most common allergen identified in our study. It was the most common allergen identified in males in our study population. Most of the patients giving positive patch test reactions to potassium dichromate were construction workers, while the rest were involved in other occupations but would occasionally do the small construction works at their houses or shops to save money. Other possible sources of exposure to chromates included use of paints, woods, glass, and cleaning products. ${ }^{24}$

\section{CONCLUSION}

Having an idea about the common allergens in a demographic area helps the clinician in pointing out the causative factors easily. Such studies are important to know the cumulative data from a particular geographical area as there can be variation in the allergen distribution which can affect the patch test profile.

Common allergens identified in our study such as nickel sulfate, potassium dichromate, cobalt sulfate, and are more or less similar to studies from other parts of India.

\section{ACKNOWLEDGEMENT}

We sincerely thank the dean and staff of Vinayaka Missions Medical College \& Hospitals, Karaikal for their immense support in completion of this study.

\section{REFERENCES}

1. Mendenhall RG, Ramsay DL, Girard RA. A study of the practice of dermatology in the United States. Arch Dermatol 1978;1 14:1456-62.

2. Thyssen JP, Linneberg A, Menné T, Johansen JD. The epidemiology of contact allergy in the general population - Prevalence and main findings. Contact Dermat 2007;57:287-99.

3. Reed JT, Ghadially R, Elias PM. Skin type, but neither race nor gender, influence epidermal permeability barrier function. Arch Dermatol 1995;131:1134-8.

4. Mortz CG, Lauritsen JM, Bindslev-Jensen C, Andersen KE. Prevalence of atopic dermatitis, asthma, allergic rhinitis, and hand and contact dermatitis in adolescents: The Odense Adolescence Cohort Study on Atopic Diseases and Dermatitis. BrJDermatol 2001;144:523-32.

5. Stables GI, Forsyth A, Lever RS. Patch testing in children. Contact Dermatitis 1996;34:341-4.

6. Katsarou A, Koufou V, Armenaka M, Kalogeromitros D, Papanayotou G, Vareltzidis A. Patch tests in children: A review of 14 years experience. Contact Dermatitis 1996;34:70-1.

7. Sevila A, Romaguera C, Vilaplana J, Botella R. Contact dermatitis in children. Contact Dermatitis 1994:30:292-4.

8. Belsito DV. The diagnostic evaluation, treatment, and prevention of allergic contact dermatitis in the new millennium. J Allergy Clin Immunol 2000;105:409-20.

9. Sasseville D. Occupational contact dermatitis. Allergy Asthma Clin Immunonol 2008;4:59-65.

10. Diepgen TL. Occupational skin-disease data in Europe. Int Arch Occup Environ Health 2003;76:331-8.

11. Bajaj AK, Saraswat A, Mukhija G, Rastogi S, Yadav S. Patch testing experience with 1000 patients. Indian J Dermatol Venereol Leprol 2007;73:313-8.

12. Wilkinson DS, Fregert S, Magnusson B, Bandmann HJ, Calnan CD, Cronin E, et al. Terminology of contact dermatitis. Acta Derm Venereol (Stockh) 1970;50:287-92

13. Bruynzeel DP, Ferguson J, Andersen K, Goncalo M, English J, Goossens A, et al Photopatch testing: A consensus methodology for Europe. J Eur Acad DermatolVenereol 2004;18:679-82.

14. Bourke J, Coulson I, English J. Guidelines for care of contact dermatitis. Br J Dermatol 2001;145:877-85.

15. Hassan I, Rather PA, Jabeen Y, Wani ZA, Altaf H, Nisa N, et al. Preliminary experience of patch testing at Srinagar, Kashmir. Indian J Dermatol Venereol Leprol 2013;79:813-6.

16. Hassan I, Akhtar S, Zeerak S, Rasool F, Rather PA, Bhat YJ, et al. Clinicoepidemiological and patch test profile of patients attending the contact dermatitis clinic of a tertiary care hospital in north India: A 7-year retrospective study. Indian Dermatol Online J2019;10:669-75.

17. Sarma N, Ghosh S. Clinico-allergological pattern of allergic contact dermatitis among 70 Indian children. Indian J Dermatol Venereol Leprol 2010;76:38-44

18. Sadagopan K, Kalappan D, Sivaprakasam N, Vinoth. Patch test results from an occupational and contact dermatitis clinic in a tertiary care hospital of southern India:A retrospective study.J Clin Diagn Res 2017;1 1:11-4.

19. Iraji F, Asilian A, Enshaieh S, Shamoradi Z, Faghihi G. Contact dermatitis in cement workers in Isfahan. Indian J Dermatol 2006;51:30-32.

20. Sharma V, Mahajan VK, Mehta KS, Chauhan PS. Occupational contact dermatitis among construction workers: Results of a pilot study. Indian J DermatolVenereol Leprol 2014;80:159-61.

21. Handa S, Jindal R. Patch test results from a contact dermatitis clinic in North India. Indian JDermatolVenereol Leprol 201 1;77:194-6.

22. Beck MH, Wilkinson SM. Contact Dermatitis: Allergic. In: Burns T, Breathnach S, Cox N, Griffiths C, editors. Rook's Textbook of Dermatology. West-Sussex, UK:Wiley-Blackwell;2010.p.2:1130.

23. Goh CL, Kowk SF, Gan SL. Cobalt and nickel content of Asian cements. Contact Dermatitis 1986;15:169-72.

24. Sharma VK, Asati DP. Pediatric contact dermatitis. Indian J Dermatol Venereol Leprol 2010;76:514-20.

25. Shenoi DS, Srinivas CR, Balachandran C. Results of patch testing with a standard series of allergens at Manipal. Indian J Dermatol Venereol Leprol 1994;60:133-5.

\section{Conflicts Of Interest}

There are no conflicts of interest. 